\title{
AZUDES Y ACUEDUCTOS DEL SISTEMA DE RIEGO TRADICIONAL DE LA VEGA BAJA DEL SEGURA (ALICANTE, ESPAÑA)
}

\author{
Arturo Trapote Jaume ${ }^{1}$, José Francisco Roca Rocaㄹ y Joaquín Melgarejo Moreno ${ }^{1}$ \\ ${ }^{1}$ Instituto Universitario del Agua y las Ciencias Ambientales.Universidad de Alicante \\ ${ }^{2}$ Departamento de Ingeniería Civil. Universidad de Alicante
}

\section{RESUMEN}

En el presente trabajo se describen y analizan las principales obras hidráulicas del sistema de riego tradicional de la comarca de la Vega Baja del Segura, concretamente, los azudes y los acueductos. Los azudes de toma, construidos en el cauce del río Segura, representan el inicio del sistema, desde donde parte una extensa y compleja red de acueductos constituida por acequias y azarbes, como elementos fundamentales, que distribuyen el agua para el regadío. En este estudio se ha llevado a cabo una amplia y profunda investigación documental, tomado datos de campo y captado imágenes in situ que, junto con los diagramas aportados, resultan imprescindibles para comprender la magnitud del sistema. Los resultados obtenidos han servido no sólo para catalogar y caracterizar los elementos que integran el sistema hidráulico del regadío tradicional de la Vega Baja del Segura, sino también para poner de manifiesto un ejemplo real de optimización de recursos hídricos en una zona del sureste peninsular español de escasa e irregular pluviometría. Asimismo, el estudio efectuado revela un sistema de riego sumamente eficiente desde un punto de vista cuantitativo y no tanto desde el cualitativo, debido a la presencia, entre otros contaminantes, de altas concentraciones de sales.

Palabras clave: Azud, acueducto, sistema de riego tradicional, Vega Baja del Segura, optimización de recursos hídricos, acequia, azarbe.

\section{ABSTRACT}

\section{Diversion dams and aqueducts of the Vega Baja (Segura River) traditional irrigation system} (Alicante, Spain)

This paper describes and discusses the main hydraulic works of traditional irrigation system in the Vega Baja del Segura area, particularly the diversion dams and the aqueducts. The diversion dams, built on the bed of the Segura River, represent the beginning of the system from where part a vast and complex network of aqueducts, constituted by ditches and drainage ditches, as fundamental elements that distribute water for irrigation. An extensive and thorough documentary research has been carried out in this study. Field data and in-situ images have been gathered and, along with the provided diagrams, they are essential to understand the magnitude of the system. The results have served not only to catalog and characterize the elements comprising the hydraulic system of the traditional irrigation of the Vega Baja del Segura, but also to reveal a real example of optimization of water resources in an area of the Spanish peninsular Southeast of low and irregular rainfall. In addition, the study reveals a system of highly efficient irrigation from a quantitative point of view and not so much in the qualitative due to the presence of high concentrations of salts, among other pollutants.

Keywords: Diversion dam, aqueduct, traditional irrigation system, Vega Baja del Segura, optimization of water resources, ditch, drainage ditch.

\section{INTRODUCCIÓN}

La comarca de la Vega Baja del Segura se encuentra situada al sur de la provincia de Alicante y abarca una extensión de $957,28 \mathrm{~km}^{2}$, lo que supone el 16,46\% de la superficie total de la provincia. Linda al norte con las comarcas del Medio y del Bajo Vinalopó, al este con el mar Mediterráneo y al suroeste con la Región de Murcia. 
Dentro de la comarca, la superficie de cultivo tradicional, de unos $183 \mathrm{~km}^{2}$ (Figura 1), se abastece con las aguas desviadas del río Segura mediante azudes, y son distribuidas por las tierras de cultivo a través de un conjunto de acueductos principales o acequias que configuran la denominada "red de aguas vivas". Se definen las aguas vivas como aquellas que manan y corren de forma natural antes de ser usadas para riego. Por lo tanto, son las aguas que discurren por el río y las que se derivan desde éste hacia los terrenos de cultivo. También se aplica este término cuando, una vez reunidas las aguas drenadas o avenadas de una zona de cultivo, éstas pasan aguas abajo a otra zona de cultivo para ser reutilizadas para el riego, declarándose entonces como vivas.

Figura 1. Mapa general del sistema de riegos tradicionales de la Vega Baja del Segura.

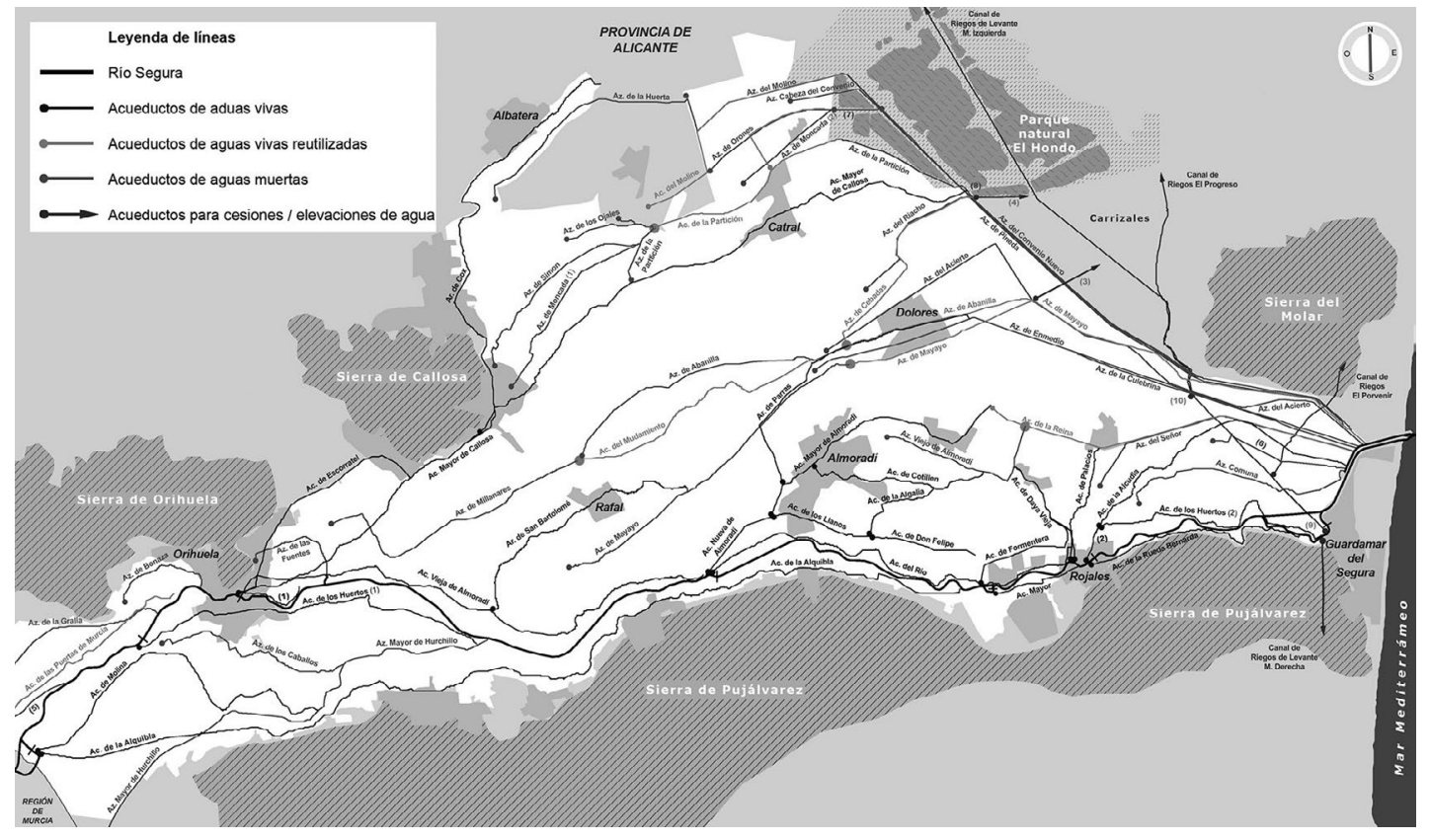

Fuente: Elaboración propia.

Debido a la baja capacidad filtrante del terreno (limo-arcilloso), se hizo necesaria la construcción de una red de acueductos de drenaje o azarbes, denominada "red de aguas muertas". Se definen las aguas muertas como aquellas procedentes de las sobrantes, drenaje o avenamiento de los riegos, además de las estancadas y sin corriente, como las que puede haber en los almarjales.

Los azarbes tienen dos funciones principales: por un lado, recoger las aguas sobrantes del regadío para devolverlas al río, evitando así el encharcamiento de los terrenos y la pudrición de las raíces de los cultivos, y, por otro, reintroducir dichas aguas en el sistema para reutilizarlas en el riego. Esta red de azarbes, denominada "red de aguas vivas reutilizadas", permite utilizar hasta tres veces las aguas antes de su devolución final al Segura, maximizándose así el aprovechamiento de los escasos recursos hídricos disponibles e incrementado la eficiencia del sistema. Una función secundaria, pero no menos importante, de la red de azarbes es la de mantener los altos niveles freáticos de la zona en cotas negativas, lo que favoreció en su momento (siglo XVIII) la implantación del cultivo de cítricos y arbolados.

En la Figura 2 se esquematiza el ciclo fundamental que realizan las aguas dentro del sistema de riego tradicional, diferenciando dos zonas: A y B.

En la zona A, las aguas vivas son desviadas del cauce del río mediante los azudes y transportadas y distribuidas mediante la red de acueductos de aguas vivas o acequias, las cuales se ramifican hasta cubrir toda su superficie regable. Una vez las aguas han sido usadas para el riego son drenadas de los terrenos a través de la red de aguas muertas o azarbes, reuniéndolas y conduciéndolas hasta un único punto para desaguarlas en el río. En esta zona, el ciclo de reutilización de las aguas se inicia en el río, cuando las aguas muertas vertidas por los azarbes llegan aguas abajo a un nuevo azud y son derivadas a otras acequias, quedando declaradas de nuevo como aguas. Dentro del perímetro del riego tradicional de la Vega Baja del Segura este ciclo se encuentra vigente en la zona de la margen derecha del río y en la zona oeste de la margen izquierda, entre Orihuela y el límite con la Región de Murcia, además de en gran parte de la 
huerta murciana. La última reutilización de las aguas del Segura se da en el $8^{\circ}$ y último azud, donde el río cede caudales para que sean elevados tanto a la margen izquierda con dirección a los campos de Crevillente y Elche como a la margen derecha con dirección a los campos de Guardamar y La Mata de Torrevieja.

Figura 2. Esquema fundamental del ciclo del agua en los regadíos tradicionales de la Vega Baja del Segura.

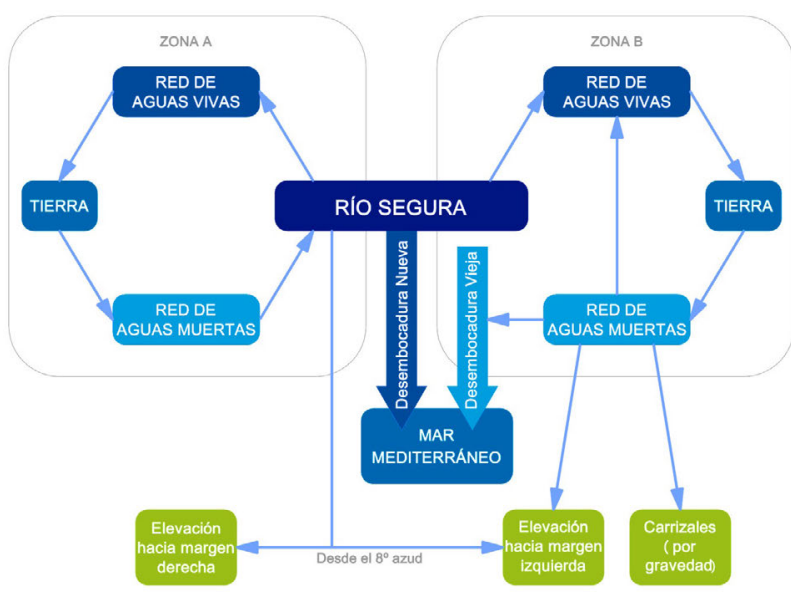

Fuente: Elaboración propia.

En la zona B, las aguas vivas son desviadas del cauce del río mediante los azudes y transportadas y distribuidas mediante la red de acueductos de aguas vivas inicial o acequias, las cuales se ramifican a lo largo y ancho de su superficie regable. Tras su utilización para el riego, las aguas son drenadas de los terrenos por la red de aguas muertas o azarbes, reuniéndolas todas. Una vez reunidas, las aguas muertas abandonan la superficie regada por la red de aguas vivas inicial y pasan a ser declaradas como vivas dentro de los mismos azarbes, volviéndose a usar en el regadío de las zonas donde no hay abastecimiento de agua por parte de la red de aguas vivas inicial. Este ciclo, donde las aguas muertas se declaran como vivas sin pasar por el río, se da hasta dos veces dentro del sistema de acequias-azarbes; por lo tanto, las mismas aguas pueden ser utilizadas hasta tres veces (Melgarejo, J. et al., 2013).

Las aguas sobrantes de las tierras regadas -por simple gravedad- con aguas utilizadas por segunda o tercera vez son cedidas a la zona de Carrizales, situada al este, en el término de Elche (comarca del Baix Vinalopó), para ser utilizadas por tercera o cuarta vez, dependiendo del azarbe de procedencia. Una vez reunidas las aguas drenadas de las tierras regadas con aguas utilizadas por segunda o tercera vez, son dirigidas mediante azarbes a la desembocadura vieja del Segura, y antes de desaguar en el río ceden parte de los caudales drenados a las comunidades/compañías de riegos que elevan las aguas hacia la margen izquierda, hasta los campos de Crevillente y Elche, para darles un tercer o cuarto uso a las aguas dependiendo del azarbe de procedencia. Este ciclo se sitúa en la margen izquierda, entre Orihuela y Guardamar del Segura.

El regadío tradicional de la Vega Baja del Segura cuenta con un singular conjunto de obras hidráulicas que dan soporte físico al sistema y que pueden clasificarse en dos grandes grupos, con funciones claramente diferenciadas pero complementarias: los azudes y los acueductos. En los primeros se realizan las tomas de agua del río y el desvío de las mismas hacia los segundos, que son los encargados de distribuir el agua por las tierras del regadío tradicional a través de una extensa y compleja red ramificada y jerarquizada de acequias y azarbes.

En el presente trabajo se lleva a cabo, precisamente, un estudio de los azudes y acueductos, elementos esenciales del sistema de riego tradicional de la comarca de la Vega Baja del Segura. Se describen sus características y se analizan sus funciones en el sistema, así como la propia eficiencia del mismo, tanto desde un punto de vista cuantitativo como cualitativo.

La metodología utilizada incluye una amplia y profunda investigación documental, toma de datos de campo e imágenes de algunos de los principales elementos del sistema, así como diagramas explicativos del funcionamiento del regadío tradicional.

Los resultados obtenidos ponen de manifiesto la existencia de un sistema de riego cuantitativamente eficiente, capaz de abastecerse con recursos propios del río Segura, y, por ende, una gestión óptima de los escasos recursos hídricos disponibles. 


\section{EL RÍO SEGURA A TRAVÉS DE LOS RIEGOS TRADICIONALES}

El río Segura es la arteria principal del sistema de riego tradicional de la Vega Baja, puesto que aporta los caudales de agua que circulan por las redes de acequias y azarbes. Se puede considerar como un río colgado", cuyo talweg no coincide con el punto más bajo del valle (Muñoz, J., 2008). Varios autores (Parra, J., 1998; Parra J., Parra, G. et al., 2006), coinciden en señalar que el río Segura fue durante el dominio musulmán desviado desde el centro del valle hacia el lado derecho del mismo, haciéndole ganar cota y aumentando superficie cultivable al valle. Dicho desvío se debió realizar con anterioridad al siglo XI, ya que de esa época hay textos musulmanes que dejan constancia de la existencia de la red de acequias y azarbes, que aún perdura en nuestros días.

El actual cauce del río Segura se debe al plan de Defensa contra Avenidas de 1987 (Real Decreto-Ley 4/1987 de 13 de noviembre), aprobado con posterioridad a las graves inundaciones y la gran avenida del río, el cual se desbordo e inundó gran parte de la Vega Baja a principios de noviembre de 1987. En Orihuela, particularmente, el río alcanzó una altura de 6,20 m, llegando a los 6,50 m en la desembocadura y anegando hasta un $60 \%$ de la huerta de Guardamar (Gil, A. et al., 2004).

El plan, diseñado con un caudal máximo de $400 \mathrm{~m}^{3} / \mathrm{s}$-para un periodo de retorno de 50 años-, incluía, entre otras actuaciones, el encauzamiento del río desde la Contraparada de Murcia hasta su desembocadura en Guardamar del Segura, el redimensionamiento de la sección del cauce y la rectificación del mismo, eliminado los meandros y acortándolo un $20 \%$, de manera que se redujo desde una longitud inicial de $48.931 \mathrm{~m}$ hasta $38.970 \mathrm{~m}$, desde Beniel hasta Guardamar.

El encauzamiento se dividió en 5 tramos: tramo Beniel-Benejúzar, tramo (intermedio) urbano de Orihuela, tramo Benejúzar-Rojales, tramo urbano de Rojales y tramo Rojales-Guardamar del Segura, que se describen seguidamente.

Tramo Beniel-Benejúzar (Figura 3). La longitud de este tramo es de $21.550 \mathrm{~m}$, con sección trapezoidal y taludes de tierra $3,5 \mathrm{H} / 1 \mathrm{~V}$, y una altura variable de entre 7,5 y $6,5 \mathrm{~m}$. En este tramo se unen al río varios azarbes, además del canal de desagüe de La Pedrera. Aquí se ubican los azudes $1^{\circ}$ y $2^{\circ}$.

Figura 3. Sección tipo del río Segura en el tramo Beniel-Benejúzar.

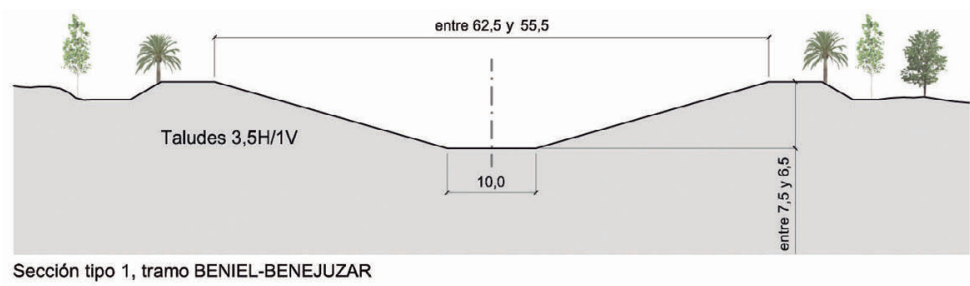

Escala $1 / 1000$, cotas on metros

Fuente: Elaboración propia.

Tramo (intermedio) urbano de Orihuela (Figura 4). La longitud de este tramo es de $1.627 \mathrm{~m}$, de sección rectangular con muros y solera de hormigón armado. Se diferencian dos tramos: los primeros $600 \mathrm{~m}$ (casco antiguo de la ciudad), con una pendiente del $2 \%$, una anchura de entre 20 y $15 \mathrm{~m}$, y una profundidad de entre 7 y $5,5 \mathrm{~m}$, y los restantes $1.000 \mathrm{~m}$ (casco moderno de la ciudad), con una pendiente del 1,5\%, una anchura de $20 \mathrm{~m}$ y una profundidad de $6 \mathrm{~m}$. En la unión entre los dos tramos se encuentran los azudes $3^{\circ}$ y $4^{\circ}$, en pleno centro urbano de Orihuela.

Figura 4. Sección tipo del río Segura en el tramo urbano de Orihuela.

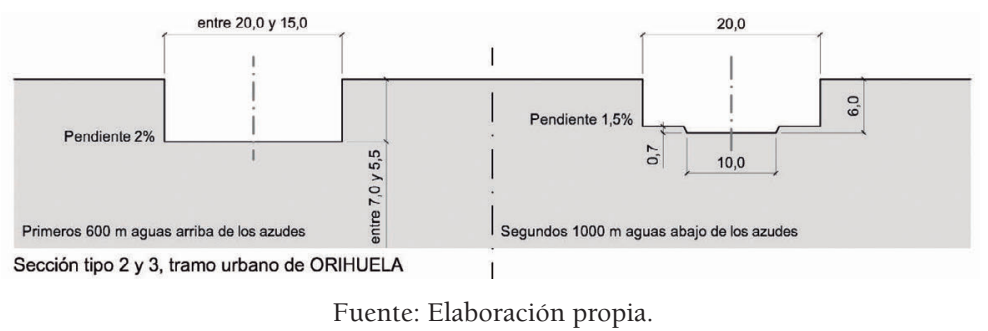

Tramo Benejúzar-Rojales (Figura 5). Inicialmente, este tramo tenía una longitud de $11.970 \mathrm{~m}$, pero posteriormente se redujo hasta unos $10.450 \mathrm{~m}$. La sección del cauce es trapezoidal, con taludes de tierra 
2,5H/1V y una profundidad variable de entre 7,5 y 6,5 m. Debido a la existencia de grupos de viviendas en las inmediaciones del cauce, se construyeron muros de contención de hormigón armado en una o ambas márgenes en vez de taludes de tierra. En este tramo se encuentran los azudes $5^{\circ}$ y $6^{\circ}$.

Figura 5. Sección tipo del río Segura en el tramo Benejúzar-Rojales.

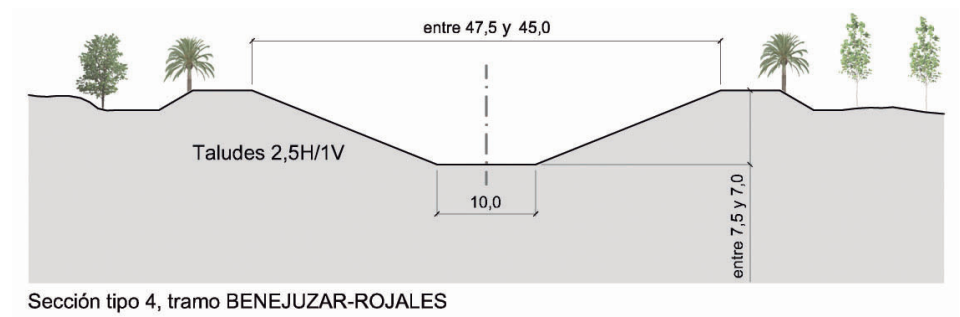

Escala $1 / 1000$, cotas en metros

Fuente: Elaboración propia.

Tramo urbano de Rojales (Figura 6). Este tramo tiene una longitud de $1.840 \mathrm{~m}$ y unas características similares a las del tramo urbano de Orihuela, con una sección rectangular con muros y solera de hormigón armado. El estrechamiento en este tramo está ocasionado por el puente de Carlos III (siglo XVIII), formado por 3 arcos sobre los cuales se apoya el tablero, y por el $7^{\circ}$ azud, que limitan el caudal circulante por el cauce.

Figura 6. Imagen del puente de Carlos III y del $7^{\circ}$ azud, en Rojales.

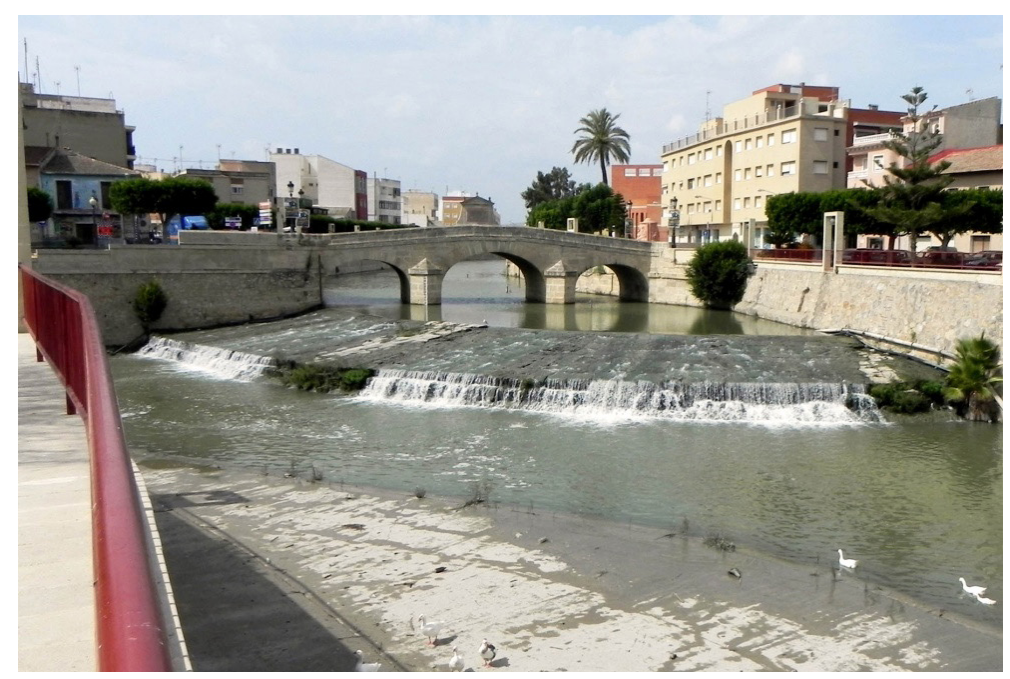

Fuente: Fotografía de los autores.

Tramo Rojales-Guardamar del Segura (Figura 7). Originalmente, la longitud del tramo era de $12.240 \mathrm{~m}$, pero después de las obras de encauzamiento se redujo un 30\%, hasta los $8.674 \mathrm{~m}$. La sección es trapezoidal, con taludes de tierra $2,5 \mathrm{H} / 1 \mathrm{~V}$, y varía desde una anchura de la base de $20 \mathrm{~m}$ con una altura de $6,5 \mathrm{~m}$ a la salida de Rojales, hasta una anchura de la base de $100 \mathrm{~m}$ con una altura de $3,5 \mathrm{~m}$ a falta de $1.000 \mathrm{~m}$ para llegar a su desembocadura. En los últimos $1.000 \mathrm{~m}$ los taludes cambian a 5H/1V.

Figura 7. Sección tipo del río Segura en el tramo Rojales-Guardamar del Segura.

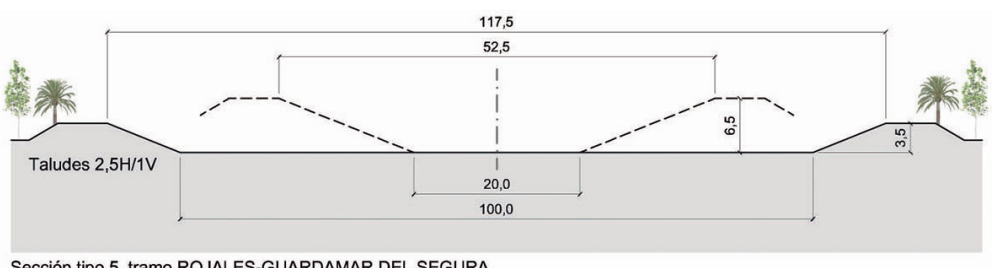

Sección tipo 5, tramo ROJALES-GUARDAMAR DEL SEGURA

Fuente: Elaboración propia. 
En los $2.000 \mathrm{~m}$ finales aparece el viejo cauce del río, paralelamente al nuevo, en la margen izquierda. La decisión de dejar el último tramo del cauce viejo junto al nuevo radica en el hecho de que en el cauce viejo desaguan los 9 mayores azarbes que drenan toda la Vega Baja del Segura, que pueden dar un caudal de $160 \mathrm{~m}^{3} / \mathrm{s}$. De esta forma se consigue independizar los caudales aportados por los azarbes de $l o s 400 \mathrm{~m}^{3} / \mathrm{s}$ que puede llevar el río. A partir de este punto, se acuñan los términos "desembocadura vieja" para el tramo del viejo cauce, donde desaguan los azarbes, y "desembocadura nueva" para el tramo del nuevo cauce paralelo al anterior (Figura 8).

Figura 8. Sección tipo del río Segura en la desembocadura.

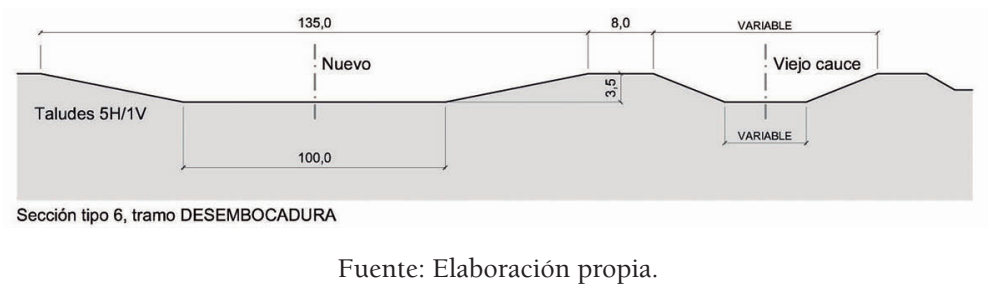

Finalmente, la desembocadura del río Segura se protege del oleaje del mar Mediterráneo, mejorando al mismo tiempo el desagüe y evitando el aterramiento, mediante un dique de escollera de $550 \mathrm{~m}$ de longitud, dispuesto en prolongación de la mota derecha y manteniendo el antiguo cauce por la izquierda (Figura 9).

Figura 9. Imagen panorámica de la desembocadura del río Segura (Guardamar), con el dique de protección en el centro, el cauce nuevo a la izquierda y el cauce viejo a la derecha.

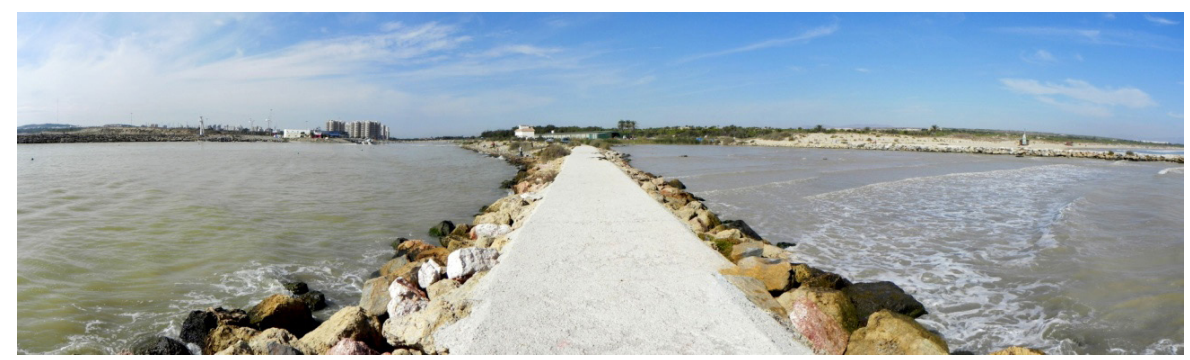

Fuente: fotografía de los autores.

\section{LOS AZUDES}

Se define "azud" como una construcción en el cauce de un río que permite la acumulación de aguas para su posterior desvío y uso. El azud es sinónimo de presa, salvando diferencias tales como que el azud no posee una excesiva altura, no sobresale del cauce del río y no almacena una gran cantidad de agua; simplemente, sirve para elevar el nivel de las aguas, haciendo posible desviarlas hacia las acequias, sin crear un embalse propiamente dicho. Una vez las aguas han alcanzado la altura del azud, lo rebasan y continúan su curso hacia aguas abajo.

Originariamente, los azudes tenían dos fines: uno, desviar las aguas para el riego de los cultivos, mediante las acequias (por gravedad y/o elevando el agua con norias accionadas por la propia energía hidráulica generada en el salto) y otro, proporcionar energía hidráulica a los molinos harineros que se situaban en las orillas del río. Por lo tanto, a lo largo del cauce se pueden encontrar azudes con una finalidad o con las dos, aunque en la actualidad la mayoría de los molinos harineros han desaparecido, se encuentran en desuso o están en estado ruinoso, algunos se han recuperado como museos etnológicos. No sucede lo mismo con el uso de los azudes como punto de partida del riego tradicional, que sigue vigente en nuestros días. Incluso, algunos azudes provistos de norias se siguen empleando para elevar agua para regar, además de formar parte del patrimonio municipal.

El río Segura cuenta con ocho azudes a su paso por la Vega Baja el Segura, que son, en sentido hacia aguas abajo (Figura 10):

- $\mathrm{N}^{\mathrm{o}}$ 1: Azud de Las Norias 
- $\mathrm{N}^{\mathrm{o}}$ 2: Azud de Los Huertos

- No 3: Azud de Almoradí

- No 4: Azud de Callosa y Catral

- No 5: Azud de Alfeitamí

- No 6: Azud de Formentera

- No 7: Azud de Rojales

- No 8: Azud de San Antonio o de Guardamar

Figura 10. Mapa de situación de los ocho azudes del río Segura a su paso por la Vega Baja.

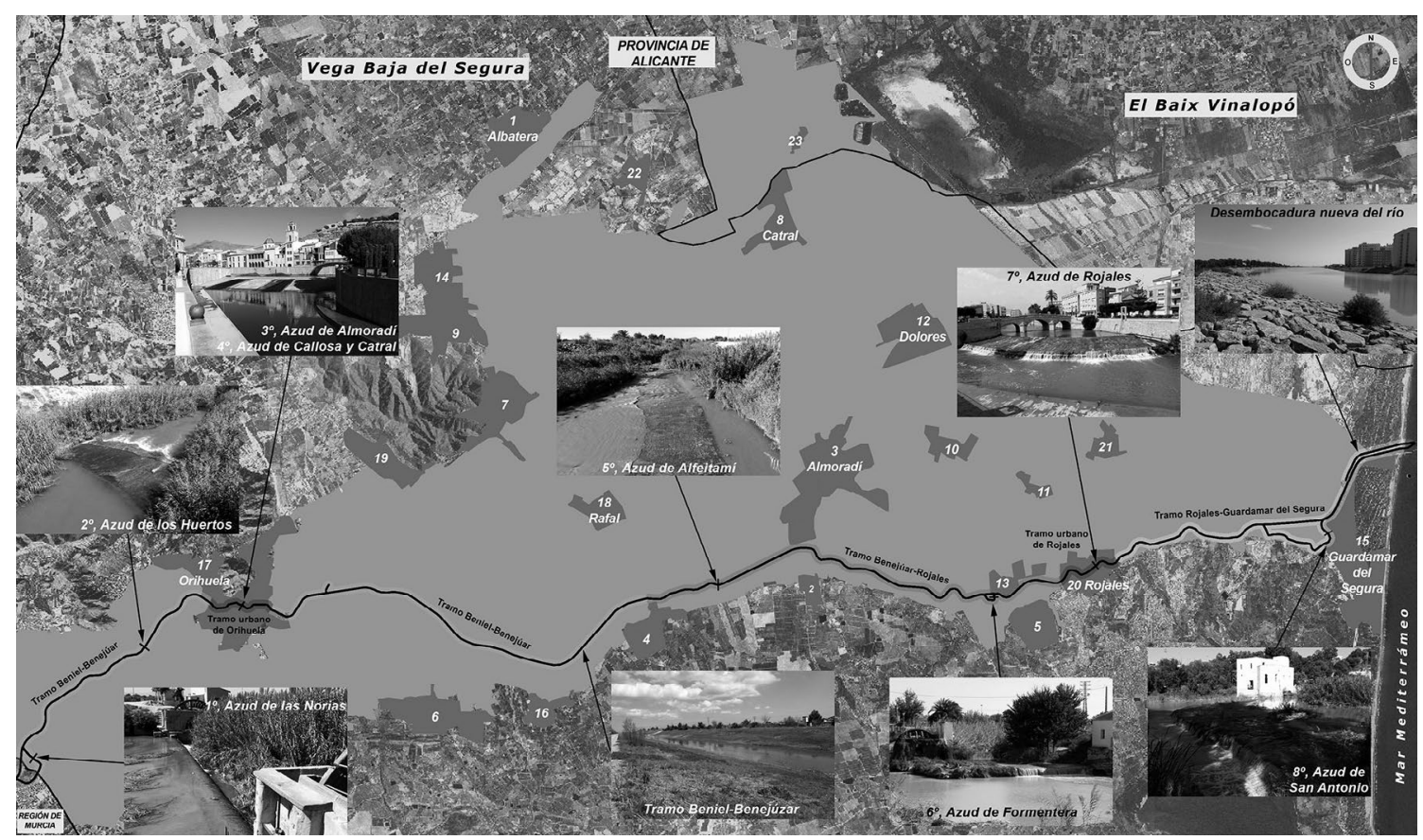

Fuente de la ortofoto: PNOA-Instituto Geográfico Nacional de España, Instituto Cartográfico Valenciano. Elaboración propia.

$\mathrm{N}^{\mathrm{o}}$ 1: Azud de Las Norias. Este azud se ubica muy cerca del límite de la provincia de Alicante con la Región de Murcia. Tras el encauzamiento y rectificación del río, este azud quedaba dispuesto de forma paralela al eje longitudinal del río y fuera del mismo. Para que el azud pudiera seguir funcionando se realizó un bypass. Se conservó un meandro de $1.440 \mathrm{~m}$, donde se quedaban el azud y las tomas de las acequias, y se conectó por sus dos extremos al nuevo cauce. Entre las conexiones de entrada y de salida del meandro se dispuso una presa hinchable, que provoca la elevación de la cota del agua desviándola del cauce nuevo hacia el meandro, pasando por el azud y devolviéndola nuevamente al cauce nuevo. Así, los caudales pequeños habituales son derivados por el meandro y las avenidas mayores pueden proseguir su curso río abajo sin pasar por aquél.

El actual azud data del siglo XVIII y es de cantería labrada (Figura 11). Tiene forma lineal y se sitúa perpendicularmente al eje del cauce antiguo del río.

Figura 11. Sección del azud de Las Norias

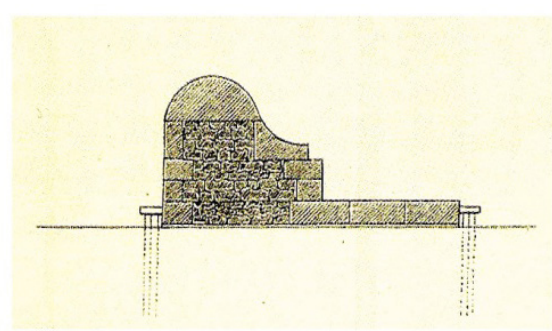

Fuente: Calvo, 2005. 
En los dos laterales del azud se sitúan sendas norias para la elevación de agua, denominadas como Moquita y Pando, y en conjunto como las Norias Gemelas (Figura 12). Aguas arriba del azud, en la margen derecha, se disponen dos boqueras para la toma de agua de las acequias de la Alquibla y de Molina.

Figura 12. Vista general del azud de Las Norias, con las Norias Gemelas a izquierda y derecha de la imagen.

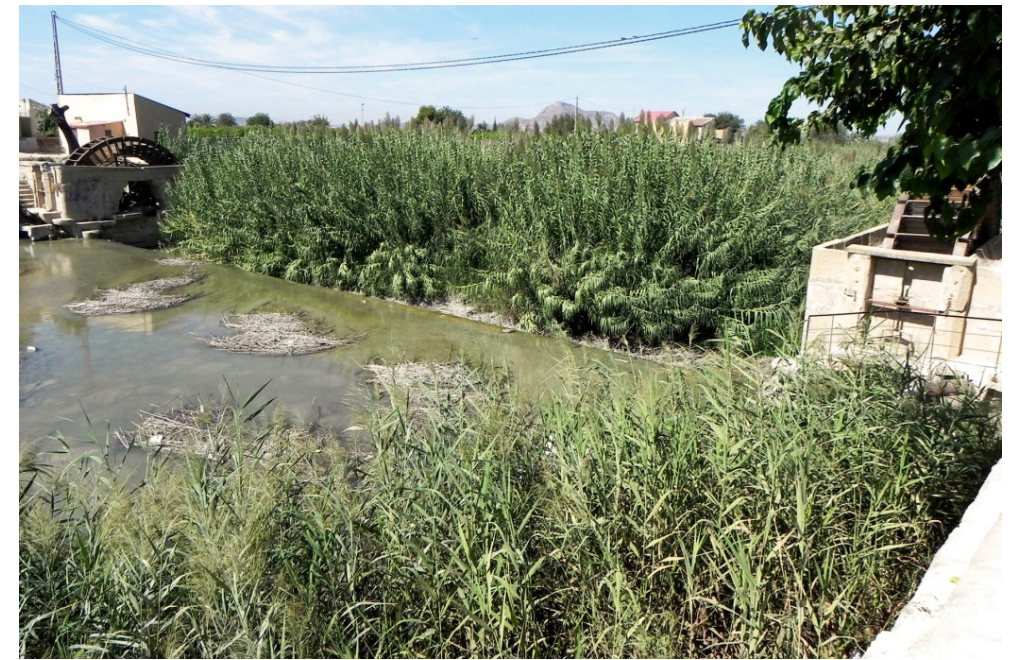

Fuente: Fotografía de los autores.

No 2: Azud de Los Huertos (Figura 13). Ubicado a $3.986 \mathrm{~m}$ aguas abajo del de Las Norias, el azud de Los Huertos, construido con sillería, tiene forma lineal y una sección en cuña, dispuesto perpendicularmente a eje del cauce del río y dentro del mismo. Aguas arriba del azud nace, en la margen derecha, la Acequia de Los Huertos.

Figura 13. Azud de Los Huertos.

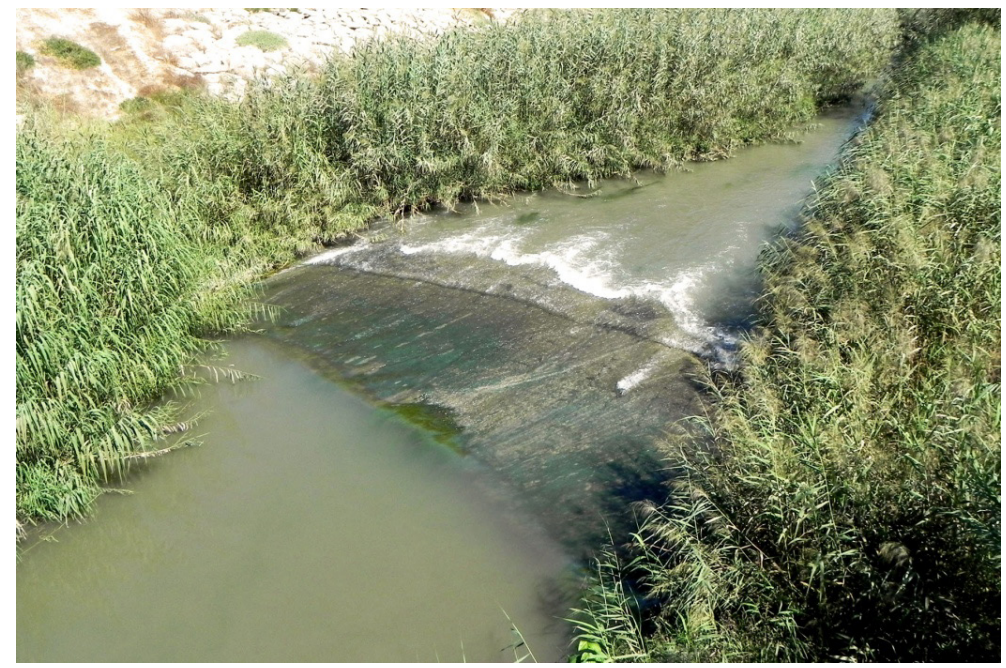

Fuente: Fotografía de los autores.

No 3: Azud de Almoradí. Situado en pleno centro de Orihuela, a $3.036 \mathrm{~m}$ aguas abajo del de Los Huertos. Datado el actual en 1430, tiene forma poligonal y una sección en cuña (Figura 14), construido con sillería, se emplaza oblicuamente respecto al eje del cauce y dentro del mismo. Cabe destacar que este azud dispone de una abertura con forma de canal, denominado "chorrera", en su mitad derecha. Dicha abertura tiene por objeto ceder aguas al siguiente azud sin necesidad de que estas lo salten. De este azud nacen, en la margen izquierda, las acequias Vieja de Almoradí, de Escorratel y de Almoravit. Este azud tuvo en la antigüedad un molino harinero en su lado derecho, denominado Molino de Masquefa, del cual no queda en la actualidad resto alguno. 
Figura 14. Vista de los azudes $3^{\circ}$, de Almoradí, y $4^{\circ}$, de Callosa y Catral, con las tomas de las acequias ubicadas en ellos.

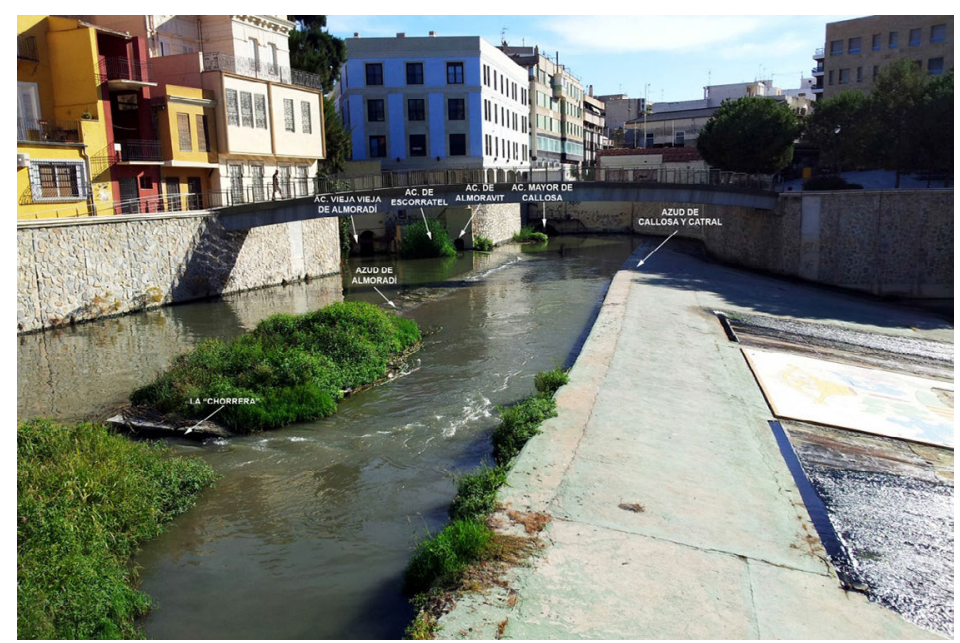

Fuente: Fotografía de los autores.

No 4: Azud de Callosa y Catral. Separado por escasos metros del azud de Almoradí se encuentra el azud de Callosa y Catral. Es de forma lineal y tiene una sección en cuña, construido con sillería y dispuesto en una posición oblicua respecto al eje del cauce, en paralelo al anterior y dentro del cauce (Figura 15). Es ligeramente más alto que el de Almoradí y se encuentra comunicado con éste mediante la abertura de la chorrera, que le cede agua. El actual azud data de 1334, aunque con motivo de las obra del encauzamiento fue revestido en su cara de aguas abajo con una solera de hormigón, y se dispuso sobre él un mosaico cerámico con la imagen del escudo de Orihuela. De este azud nace la acequia Mayor de Callosa. $\mathrm{Al}$ igual que el anterior, este azud también tuvo un molino harinero en su lateral derecho, denominado Molino de Cox, y del cual, en la actualidad, tampoco queda resto alguno.

Figura 15. Vista general desde aguas abajo del azud de Callosa y Catral, en Orihuela.

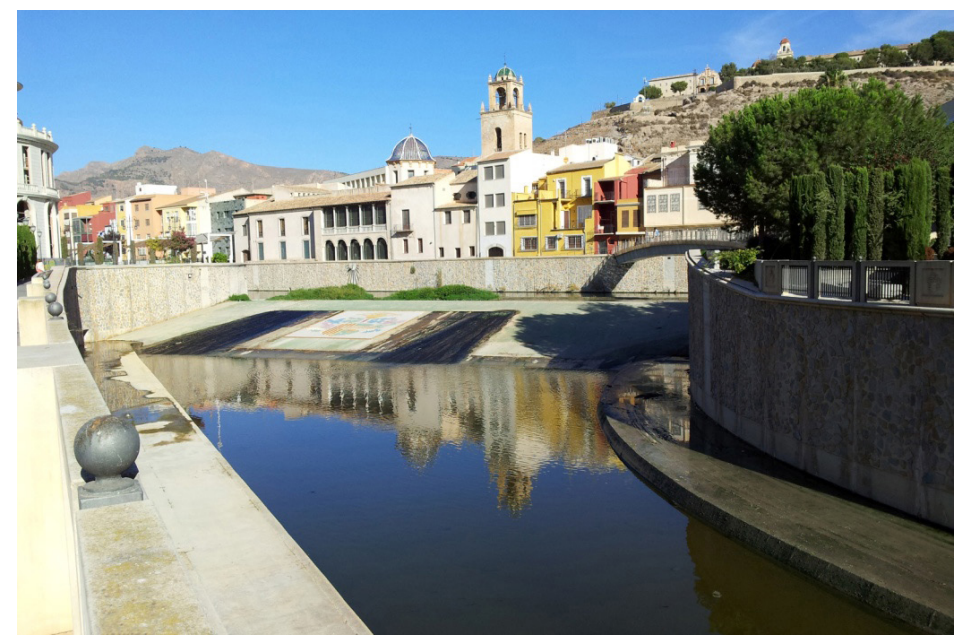

Fuente: Fotografía de los autores.

No 5: Azud de Alfeitamí. Entre los municipios de Benejúzar y Almoradí, a $12.393 \mathrm{~m}$ del azud anterior, se ubica el azud de Alfeitamí (Figura 16). Originalmente construido para mover un molino harinero homónimo, posteriormente se le abrieron dos tomas en la margen izquierda del río para las acequias Nueva de Almoradí y del Río. El primitivo azud estaba formado por estacas, hasta que en 1571 se decidió abrir las boqueras de las acequias y construir un nuevo azud permanente, terminando el conjunto de las obras en 1615. El azud tiene forma lineal y una sección en cuña, construido con sillería y dispuesto en una posición oblicua respecto al eje del cauce y dentro del mismo. Del molino quedan en la actualidad algunos restos. 
Figura 16. Azud de Alfeitamí.

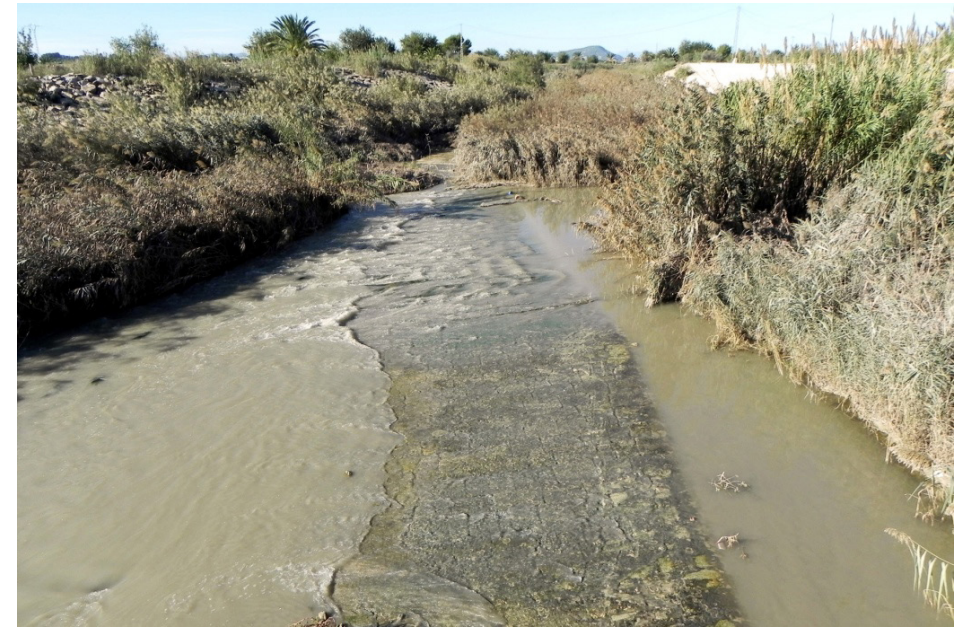

Fuente: Fotografía de los autores.

No 6: Azud de Formentera. A una distancia de $7.351 \mathrm{~m}$ del azud de Alfeitamí, entre los municipios de Formentera y Benifójar, se encuentra el azud de Formentera (Figura 17). Emplazado de manera análoga al azud de Las Norias (en un meandro del antiguo cauce) y comunicado también por sus dos extremos con el cauce nuevo, funciona de la misma forma que aquél, esto es, los caudales habituales se desvían por el meandro pasando por el azud y las avenidas con mayor caudal saltan la presa que desvía el agua hacia el meandro, continuando el curso hacia aguas abajo por el cauce nuevo. Data de 1659 y está construido con sillería. Tiene forma lineal y una sección casi rectangular, con una ligera pendiente en la cara superior, y dispuesto perpendicularmente al eje del cauce antiguo. Aguas arriba de él se ubican las tomas de las acequias de Nueva de Formentera y Mayor. Este azud cuenta con una noria en su lateral derecho, todavía en uso, y con un molino harinero en el izquierdo, denominado Molino de Formentera del Segura, conservado como museo.

Figura 17. Imagen del azud de Formentera, con la noria a la derecha y el molino harinero a la izquierda.

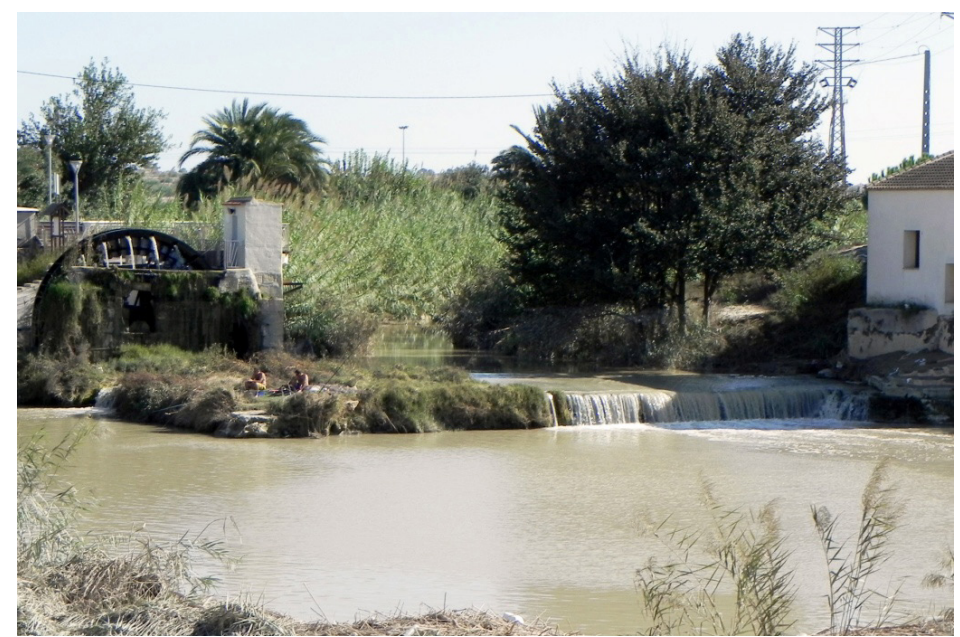

Fuente: Fotografía de los autores.

$\mathrm{N}^{\circ}$ 7: Azud de Rojales. En pleno casco urbano de Rojales, a una distancia de $2.594 \mathrm{~m}$ y justo tras pasar el puente de Carlos III, se ubica el azud de Rojales (Figura 18). Tiene forma de $1 / 4$ de circunferencia, naciendo tangencialmente del lateral derecho del cauce y muriendo perpendicularmente en el lateral izquierdo. Es de sección trapezoidal, con la cara superior inclinada, construido con sillería y situado dentro del cauce del río, perpendicularmente al eje del mismo. En su lado derecho el azud posee una noria, denominada Rueda Bernarda, y antaño tuvo un molino harinero. Aguas arriba de este azud, a la izquierda, nacen las acequias de Daya Vieja, de Palacios y Comuna, y, a la derecha, la de Rueda Bernarda. 
Figura 18. Azud de Rojales.

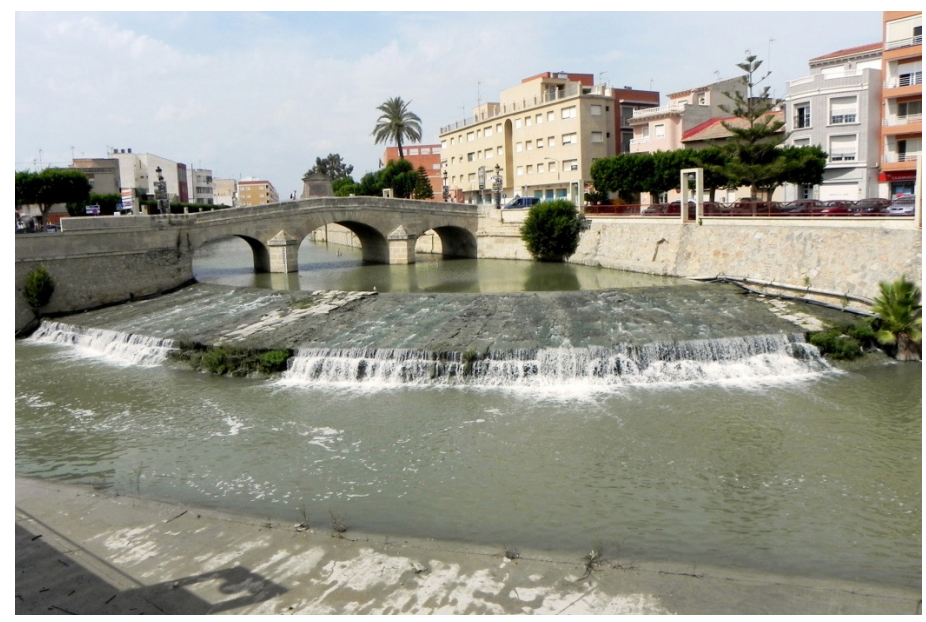

Fuente: Fotografía de los autores.

No 8: Azud de San Antonio o de Guardamar (Figura 19). Último azud del río Segura, muy cercano a su desembocadura. Dista $6.483 \mathrm{~m}$ del azud de Rojales y está situado en Guardamar del Segura. El emplazamiento de este azud es similar al del azud de Las Norias, ubicado en un tramo del cauce viejo de $2.440 \mathrm{~m}$ de longitud. Llegado el punto donde nace el tramo antiguo, los caudales habituales son desviados hacia él, pasando por el azud y devueltos al cauce nuevo. Las avenidas mayores saltan la pequeña presa que desvía los caudales hacia el cauce viejo, siguiendo su curso por el cauce nuevo hacia la desembocadura. Está construido con sillería, de forma poligonal y sección trapezoidal, con la cara superior en pendiente, dispuesto perpendicularmente a eje del cauce antiguo. Este azud no tiene una especial relevancia en el sistema de riego tradicional de la Vega Baja, ya que de él no nace ninguna acequia importante, pero es vital para conseguir el máximo aprovechamiento de las aguas del Segura. En este punto nace el Canal de Riegos de Levante Margen Izquierda, que inicialmente por gravedad y posteriormente con elevaciones lleva las aguas sobrantes del río y de los azarbes hacia los campos de Crevillente, Elche y alrededores. También nace, mediante elevación, el Canal de Riegos de Levante Margen Derecha, que lleva las aguas sobrantes del río a los campos de Guardamar y a La Mata de Torrevieja.

Figura 19. Azud de de San Antonio o de Guardamar.

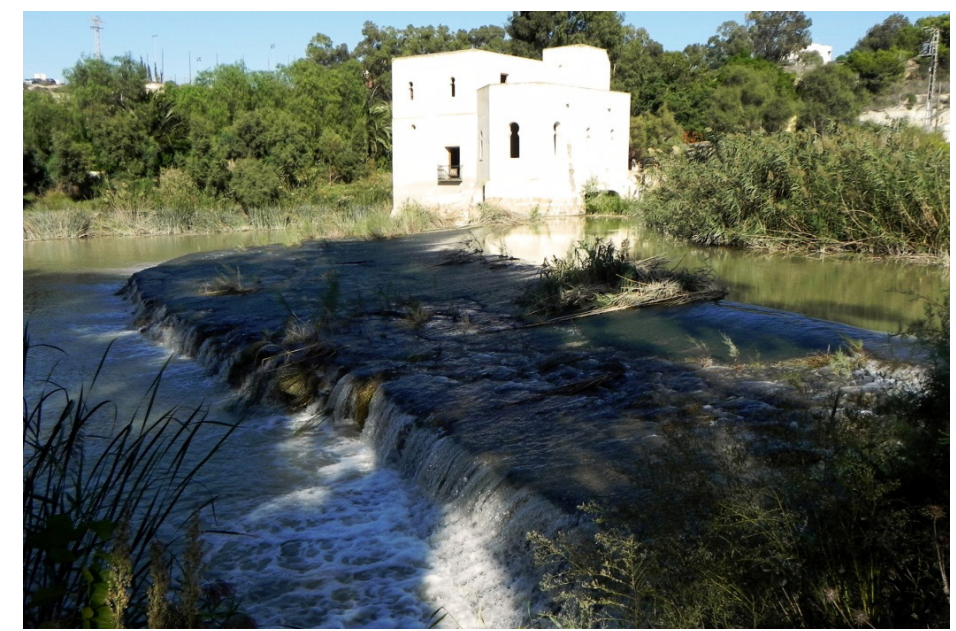

Fuente: Fotografía de los autores.

\section{LOS ACUEDUCTOS}

Los acueductos del regadío tradicional de la Vega Baja del Segura configuran tres redes: la red de aguas vivas, la red de aguas vivas reutilizadas y la red de aguas muertas. 


\subsection{La red de acueductos de aguas vivas}

Constituyen la red de aguas vivas el conjunto de acueductos encargados de conducir y distribuir las aguas de riego. La denominación de acequias se otorga a los acueductos que toman las aguas directamente del río Segura, mientras que la denominación de azarbes se mantiene en aquellos acueductos que, a pesar de distribuir aguas declaradas como vivas y usarlas para el regadío, obtienen sus caudales de las aguas drenadas por ellos mismos (aguas arriba) o por otros azarbes que se las ceden. No obstante, hay algunas excepciones que no cumplen estas reglas de denominación. Elementos característicos de esta red son las tomas de las acequias o boqueras, ubicadas en la margen del río, aguas arriba del azud, que permiten que las aguas se dirijan hacia ella. Siempre disponen de una compuerta para regular los caudales.

Los acueductos principales, en número de 15 y denominados acequias madres o mayores, toman sus aguas directamente del río Segura, a través de los 7 primeros azudes. Desde las acequias madres nacen acueductos subalternos que, dependiendo del tamaño de los mismos y de la superficie regada por cada uno, ostentan rangos diferentes. Los rangos de mayor a menor de los acueductos, después de las acequias madres, son las arrobas o acequias menores, siendo los acueductos más grandes los que toman agua de sus respectivas acequias madres. Los brazales son más pequeños que las arrobas, y pueden nacer desde ellas o desde las acequias madres. Las hijuelas son acueductos menores que los brazales, que toman agua desde ellos o desde las arrobas y derivan las aguas directamente a tierra. Además, en muchos casos, las tierras linderas a las acequias madres, arrobas y brazales se riegan directamente desde ellas.

Dentro del conjunto de la red de distribución de aguas vivas se pueden diferenciar tres redes: la red de distribución primaria, compuesta por las acequias mayores o madres, la red secundaria, compuesta por las arrobas o acequias menores y los brazales, y la red terciaria, compuesta por las hijuelas (Figura 20).

Figura 20. Esquema de la jerarquía de los acueductos existentes en la red de aguas vivas y clasificación de los mismos en función de la red a que pertenece.

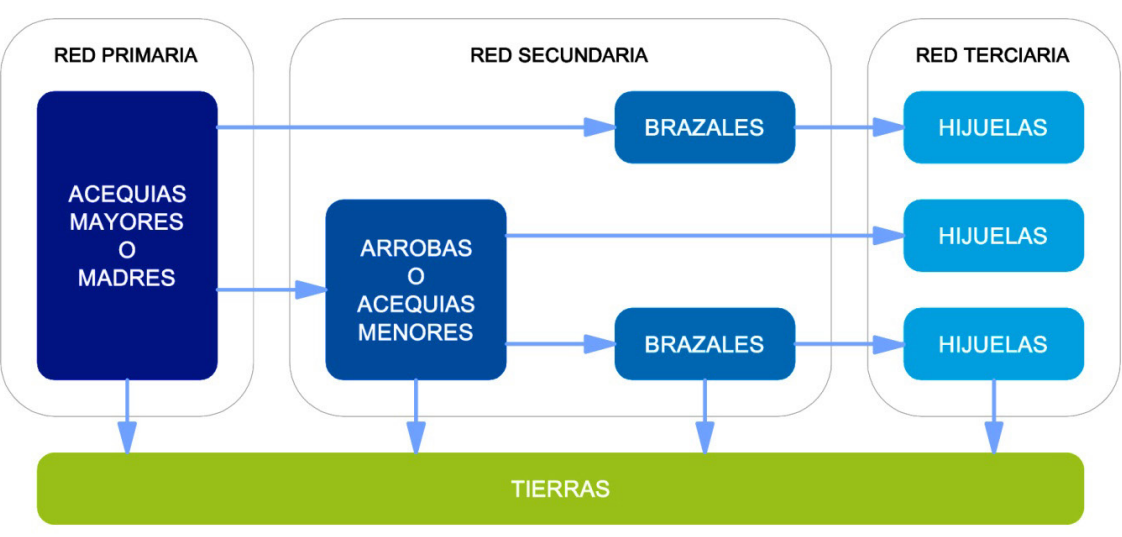

Fuente: Elaboración propia.

Los 25 acueductos principales que integran la red de aguas vivas tienen una longitud total de $168,72 \mathrm{~km}$ y cubren una superficie de $14.052 \mathrm{ha}\left(140,52 \mathrm{~km}^{2}\right)$. En la Tabla 1 se recogen las características de estos acueductos.

Tabla 1. Características de los acueductos de la red de aguas vivas.

\begin{tabular}{|c|c|c|c|c|c|c|}
\hline \multirow{2}{*}{ Margen } & \multirow{2}{*}{ Azud } & \multirow{2}{*}{ Nombre del acueducto } & \multicolumn{2}{|c|}{ Superficie regada } & \multicolumn{2}{|c|}{ Longitud } \\
\hline & & & ha & $\mathrm{km}^{2}$ & $\mathrm{~m}$ & $\mathrm{~km}$ \\
\hline Derecha & $1^{\circ}$ & Acequia de la Alquibla & 1.130 & 11,30 & 23.890 & 23,89 \\
\hline Derecha & $1^{\circ}$ & Acequia de Molina & 899 & 8,99 & 8.710 & 8,71 \\
\hline Derecha & $2^{\circ}$ & Acequia de los Huertos (1) & 734 & 7,34 & 8.600 & 8,60 \\
\hline Izquierda & $3^{\circ}$ & Acequia de Almoravit & 17 & 0,17 & 1.750 & 1,75 \\
\hline \multirow[t]{2}{*}{ Izquierda } & $3^{\circ}$ & Acequia Vieja de Almoradí & 1.890 & 18,90 & 12.180 & 12,18 \\
\hline & & Arroba de San Bartolomé & & & 6.560 & 6,56 \\
\hline \multirow[t]{2}{*}{ Izquierda } & $4^{\circ}$ & Acequia Mayor de Callosa & 4.680 & 46,80 & 20.780 & 20,78 \\
\hline & & Arroba de Cox & & & 11.980 & 11,98 \\
\hline Izquierda & $3^{\circ}$ & Acequia de Escorratel & 301 & 3,01 & 5.770 & 5,77 \\
\hline Izquierda & $5^{\circ}$ & Acequia del Río & 272 & 2,72 & 9.760 & 9,76 \\
\hline
\end{tabular}




\begin{tabular}{|c|c|c|c|c|c|c|}
\hline \multirow[t]{7}{*}{ Izquierda } & $5^{\circ}$ & Acequia Nueva de Almoradí & 2.062 & 20,62 & 2.030 & 2,03 \\
\hline & & Acequia Mayor de Almoradí & & & 6.730 & 6,73 \\
\hline & & Arroba de Parras & & & 7.250 & 7,25 \\
\hline & & Acequia de Cotillen & & & 4.430 & 4,43 \\
\hline & & Acequia de los Llanos & & & 2.340 & 2,34 \\
\hline & & Acequia de la Algalia & & & 2.190 & 2,19 \\
\hline & & Acequia de Don Felipe & & & 2.540 & 2,54 \\
\hline Izquierda & $6^{\circ}$ & Acequia de Formentera & 150 & 1,50 & 3.230 & 3,23 \\
\hline Derecha & $6^{\circ}$ & Acequia Mayor & 78 & 0,78 & 2.160 & 2,16 \\
\hline Izquierda & $7^{\circ}$ & Acequia de Daya Vieja & 273 & 2,73 & 2.800 & 2,80 \\
\hline Izquierda & $7^{\circ}$ & Acequia de Palacios & 202 & 2,02 & 2.880 & 2,88 \\
\hline Derecha & $7^{\circ}$ & Acequia de la Rueda Bernarda & 84 & 0,84 & 5.620 & 5,62 \\
\hline \multirow[t]{4}{*}{ Izquierda } & $7^{\circ}$ & Acequia Comuna & 1.280 & 12,80 & 730 & 0,73 \\
\hline & & Acequia de la Alcudia & & & 7.300 & 7,3 \\
\hline & & Acequia de los Huertos (2) & & & 6.510 & 6,51 \\
\hline & & Totales & 14.052 & 140,52 & 168,720 & 168,72 \\
\hline
\end{tabular}

Fuente: Elaboración propia.

Cabe destacar, que un tercio de la superficie total irrigada por la red de aguas vivas es regada únicamente por la acequia Mayor de Callosa, la que más territorio abarca de todas, tomando ésta sus aguas en el $4^{\circ}$ azud (de Callosa y Catral), en pleno centro urbano de Orihuela, alcanzado una longitud de 20,78 km, la segunda de mayor longitud. Sólo la acequia de la Alquibla, con 23,89 km, supera en longitud a la acequia Mayor de Callosa. Sin embargo, solo riega el 8\% de la superficie total irrigada por la red de aguas vivas.

Las acequias nacidas de los 4 primeros azudes son las de mayor longitud, y discurren cuasi paralelamente al río (las de Alquibla, Molina, Huertos (1), Vieja de Almoradí, Mayor de Callosa y Escorratel). Las acequias que nacen del $5^{\circ}$ azud, el de Alfeitamí, son acequias de menor longitud. La acequia del Río discurre paralelamente al Segura y sin una gran ramificación. No así la acequia Nueva de Almoradí, que aunque también discurre cuasi paralelamente al río posee una alta ramificación, llegando a tener 6 acueductos subalternos de gran importancia que abarcan toda su superficie regable. Las acequias nacidas hacia la marguen izquierda, en los últimos azudes $\left(6^{\circ}\right.$ y $\left.7^{\circ}\right)$, discurren, con carácter general, perpendicularmente al río y son las de menor recorrido, a excepción de las acequias de la Alcudia y de los Huertos (2), que tras tomar aguas de la acequia Comuna discurren prácticamente paralelamente al río y tienen una mayor longitud. Las acequias nacidas en la margen derecha de estos azudes discurren paralelamente al río en toda su longitud.

En general, los acueductos de aguas vivas tienen unos trazados irregulares y serpenteantes, con muchos cambios de dirección.

\subsection{La red de acueductos de aguas vivas reutilizadas}

La red de acueductos de aguas vivas reutilizadas está formada por 8 acueductos, denominados como acequias o azarbes en función de la jurisdicción a la que pertenezcan. Mediante esta red se reintroducen en el sistema una parte de las aguas sobrantes del regadío (el resto se drena al río) para reutilizarlas en el riego, hasta tres veces, antes de devolverlas, finalmente, al río.

La longitud total de los acueductos de esta red es de 54,08 km, e irrigan una superficie de 4.269 ha $\left(42,69 \mathrm{~km}^{2}\right)$. Sus correspondientes características se recogen en la Tabla 2.

TABLA 2. Características de los acueductos de la red de aguas vivas reutilizadas

\begin{tabular}{|c|c|c|c|c|c|c|}
\hline \multirow{2}{*}{ Margen } & \multirow{2}{*}{ Nombre del acueducto } & \multirow{2}{*}{ Cesiones } & \multicolumn{2}{|c|}{ Superficie regada } & \multicolumn{2}{|c|}{ Longitud } \\
\hline & & & ha & $\mathrm{km}^{2}$ & $\mathbf{m}$ & $\mathrm{km}$ \\
\hline Izquierda & Acequia de las Puertas de Murcia & & 596 & 5,96 & 5.400 & 5,40 \\
\hline Izquierda & Acequia del Mudamiento & & 593 & 5,93 & 6.240 & 6,24 \\
\hline Izquierda & Azarbe de la Reina & $\checkmark$ & 670 & 6,70 & 8.720 & 8,72 \\
\hline Izquierda & Azarbe de Mayayo & $\checkmark$ & 783 & 7,83 & 12.990 & 12,99 \\
\hline Izquierda & Azarbe de Abanilla & & 311 & 3,11 & 4.400 & 4,40 \\
\hline Izquierda & Acequia de la Partición & & 542 & 5,42 & 4.970 & 4,97 \\
\hline \multirow[t]{2}{*}{ Izquierda } & Acequia del Molino & & 409 & 4,09 & 6.180 & 6,18 \\
\hline & & Totales & 4.269 & 42,69 & 54.080 & 54,08 \\
\hline
\end{tabular}

Fuente: Elaboración propia. 
Todos los acueductos de esta red poseen una dirección paralela o cuasi paralela al río, y están situados en la margen izquierda del mismo.

La acequia de las Puertas de Murcia es la única que recibe aguas drenadas directamente de la Región de Murcia. El resto de acueductos de la red recibe sus aguas para el riego de los avenamientos recogidos por los azarbes de aguas muertas, aguas arriba de ellos. Estos azarbes de aguas muertas pueden ser las prolongaciones de ellos mismos, como es el caso de la acequia de la Partición y de los azarbes de Mayayo y Abanilla, o pueden recibir las aguas desde otros azarbes, como sucede con la acequia del Mudamiento y el azarbe de la Reina. El único acueducto que no recibe sus aguas del avenamiento de otros es la acequia del Molino, la cual recibe sus aguas de los manantiales de Tusales y Ojales.

En total, se localizan 5 puntos donde las aguas muertas son declaradas como vivas para su reutilización dentro del sistema de riego tradicional, y se contabilizan un máximo de 3 usos de unas mismas aguas para el riego dentro del sistema (un primer uso más dos reutilizaciones directas), además de un cuarto uso que serían las cesiones de las mismas dentro del microsistema formado por los azarbes de Millanares, Mudamiento, Abanilla, Cebadas y Mayayo, incluido en el sistema general.

\subsection{La red de acueductos de aguas muertas}

La red de aguas muertas está formada por un conjunto de 30 acueductos principales, que suman una longitud total de 180,06 km. Son los encargados de drenar o avenar las aguas sobrantes de riego, reuniéndolas todas en un solo acueducto para desaguarlas en un único punto. La red de acueductos de aguas muertas está constituida de forma similar a la de aguas vivas, pero siguiendo un orden inverso. Es decir, esta red no parte de un único punto como las acequias, sino que nace de una infinidad de ellos por medio de los escorredores. Los escorredores son los acueductos de menor tamaño que recogen las aguas sobrantes directamente de las tierras, dirigiéndolas hacia los acueductos de mayor tamaño denominados azarbetas o azarbes menores. Las azarbetas recogen las aguas de los escorredores, además de las avenadas por ellos mismos, y las dirigen hacia los azarbes mayores. Los azarbes mayores son los principales acueductos de la red de aguas muertas. Recogen todas las aguas drenadas por los escorredores y las azarbetas y las dirigen hacia el río para desaguarlas en él, o hacia otros acueductos de riego (acequias o azarbes), declarándose sus aguas muertas como vivas cuando éstas ganan suficiente cota para ser usadas en el riego.

Al igual que en la red de aguas vivas, en la de aguas muertas se pueden diferenciar tres redes dentro del conjunto general. La primera la red (terciaria) está compuesta por los escorredores, la segunda la red (secundaria) por las azarbetas y la tercera la red (primaria) por los azarbes mayores (Figura 21).

Figura 21. Esquema de la jerarquía de los acueductos existentes en la red de aguas muertas y clasificación de los mismos en función de la red a que pertenece.

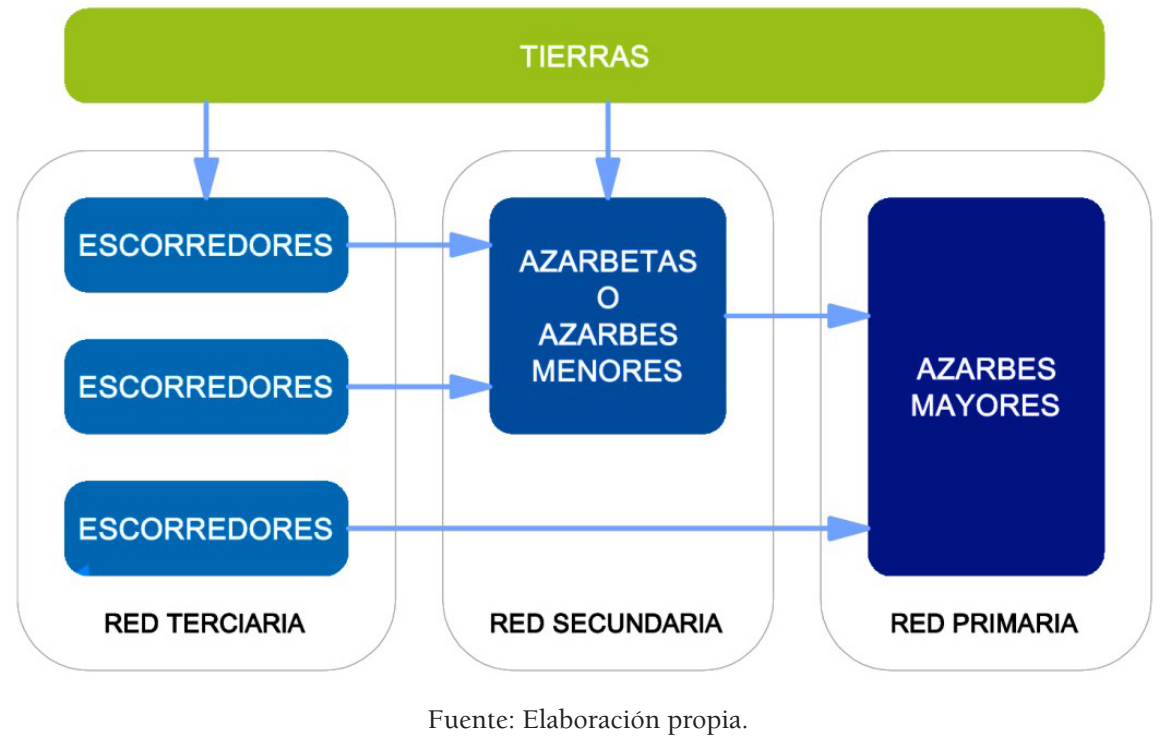

Otra forma de clasificar los acueductos de la red de aguas muertas es en los tres grupos siguientes, en función de su papel en el ciclo hídrico del sistema: los que dan sus aguas al río para que sean reutilizadas 
mediante su cauce, los que dan sus aguas a otros acueductos para que sean reutilizadas o las reutilizan ellos mismos, y los que no reutilizan sus aguas directamente, tal y como se recoge en la Tabla 3 junto con las características de cada acueducto.

Tabla 3. Características de los acueductos de la red de aguas muertas.

\begin{tabular}{|c|c|c|c|c|c|c|}
\hline \multirow[t]{2}{*}{ Margen } & \multirow[t]{2}{*}{ Nombre del acueducto } & \multicolumn{2}{|c|}{$\begin{array}{l}\text { Reutilización directa de sus } \\
\text { aguas mediante }\end{array}$} & \multirow[t]{2}{*}{ Cesiones } & \multicolumn{2}{|c|}{ Longitud } \\
\hline & & Río & Otros acueductos & & $\mathrm{m}$ & $\mathrm{km}$ \\
\hline Derecha & Azarbe Mayor de Hurchillo & $\checkmark$ & & & 11.530 & 11,53 \\
\hline Derecha & Azarbe de los Caballos & $\checkmark$ & & & 4.910 & 4,91 \\
\hline Izquierda & Azarbe del Merancho & $\checkmark$ & & & 2.130 & 2,13 \\
\hline Izquierda & Azarbe de la Gralla & $\checkmark$ & & & 4.960 & 4,96 \\
\hline Izquierda & Azarbe de Bonanza & $\checkmark$ & & & 2.580 & 2,58 \\
\hline Izquierda & Azarbe de las Fuentes & $\checkmark$ & & & 2.540 & 2,54 \\
\hline Izquierda & Azarbe de Millanares & & $\checkmark$ & & 6.940 & 6,94 \\
\hline Izquierda & Azarbe de Mayayo & & $\checkmark$ & & 8.200 & 8,20 \\
\hline Izquierda & Azarbe de Abanilla & & $\checkmark$ & & 7.120 & 7,12 \\
\hline Izquierda & Azarbe de la Partición & & $\checkmark$ & & 4.450 & 4,45 \\
\hline Izquierda & Azarbe de Moncada (1) & & $\checkmark$ & & 4.750 & 4,75 \\
\hline Izquierda & Azarbe de Simón & & $\checkmark$ & & 4.970 & 4,97 \\
\hline Izquierda & Azarbe de los Ojales & & $\checkmark$ & & 2.610 & 2,61 \\
\hline Izquierda & Azarbe Viejo de Almoradí & & $\checkmark$ & & 4.340 & 4,34 \\
\hline Izquierda & Azarbe Comuna & & & & 5.640 & 5,64 \\
\hline Izquierda & Az. de la Villa de Guardamar & & & & 3.370 & 3,37 \\
\hline Izquierda & Azarbe del Señor & & & $\checkmark$ & 6.560 & 6,56 \\
\hline Izquierda & Azarbe de la Culebrina & & & $\checkmark$ & 6.720 & 6,72 \\
\hline Izquierda & Azarbe de Enmedio & & & $\checkmark$ & 13.160 & 13,16 \\
\hline Izquierda & Azarbe del Acierto & & & $\checkmark$ & 14.730 & 14,73 \\
\hline Izquierda & Azarbe de Pineda & & & $\checkmark$ & 10.800 & 10,80 \\
\hline Izquierda & Azarbe del Riacho & & & $\checkmark$ & 10.210 & 10,21 \\
\hline Izquierda & Azarbe del Convenio Nuevo & & & & 13.330 & 13,33 \\
\hline Izquierda & Azarbe de la Huerta & & & & 5.550 & 5,55 \\
\hline Izquierda & Azarbe del Molino & & & & 5.790 & 5,79 \\
\hline Izquierda & Azarbe Cabeza del Convenio & & & & 4.200 & 4,20 \\
\hline Izquierda & Azarbe de Orones & & & & 3.250 & 3,25 \\
\hline Izquierda & Azarbe de Moncada (2) & & & & 2.650 & 2,65 \\
\hline Izquierda & Trozo de Higueras & & & & 1.670 & 1,67 \\
\hline \multirow[t]{2}{*}{ Izquierda } & Azarbe del Convenio Viejo & & $\checkmark$ & & 400 & 0,40 \\
\hline & & & & Totales & 180.060 & 180,06 \\
\hline
\end{tabular}

Fuente: Elaboración propia.

Del primer grupo, los que dan sus aguas al río para su reutilización, existen 6 azarbes. El azarbe Mayor de Hurchillo, proveniente de la Región de Murcia, recoge avenamientos e introduce un importante caudal al río. Los azarbes del Merancho y de la Gralla también vienen desde la vecina región murciana, pero introducen un caudal bastante menor que el Mayor de Hurchillo. Los tres restantes, Caballo, Bonanza y Fuentes, no poseen una gran longitud y nacen dentro del sistema de riego tradicional. Todos ellos se ubican en la parte más oriental del sistema.

Del segundo grupo, los que dan sus aguas a otros acueductos para que sean reutilizadas o las reutilizan ellos mismos, existen 9 azarbes. Son, por un lado, los azarbes de Millanares, que da sus aguas a la acequia del Mudamiento, y Viejo de Almoradí, que da sus aguas al Azarbe de la Reina; por otro, los azarbes de Abanilla y Mayayo, que reutilizan sus propias aguas; y, por último, el azarbe de la Partición, que reutiliza sus propias aguas además de las que le dan los azarbes de Moncada (1), Simón y Ojales. Todos estos azarbes ocupan la parte central del sistema de riego tradicional. En este grupo quedaría por citar el azarbe del Convenio Viejo, pero el carácter especial de éste hace que más que de un azarbe sea un colector, de unos 400 metros de longitud, que pasa las aguas de la acequia Mayor de Callosa y del azarbe de la Partición al azarbe del Niño. Está situado en el paraje denominado El Paredón. 
En el tercer grupo se encuentran los restantes, que desaguan sus aguas a la desembocadura vieja del río Segura, directamente o mediante otros azarbes, sin que de ello se consiga una reutilización directa. Estos azarbes se encuentran más al límite septentrional y oriental del sistema de riego tradicional de la Vega Baja. Casi todos los acueductos de este grupo se caracterizan por unos trazados muy regulares, donde los cambios de dirección están claramente definidos, con unas alineaciones poligonales y prácticamente rectilíneas.

\section{CONCLUSIONES}

En el presente trabajo se han estudiado y analizado los azudes y acueductos del sistema de regadío tradicional de la Vega Baja del Segura, el cual ocupa una superficie total de unas $18.321 \mathrm{ha}\left(183,21 \mathrm{~km}^{2}\right)$. El río Segura suministra las aguas de riego al regadío tradicional, constituyendo la arteria principal del sistema. Discurre encauzado a lo largo de un recorrido de 38.970 m, desde Beniel hasta Guardamar del Segura.

A lo largo del cauce existen 8 azudes, cuyas características físicas y funcionales se han definido. Desde los siete primeros nace la red de acueductos de aguas vivas y son, por tanto, los puntos de inicio de los riegos tradicionales. A partir de estos azudes, los acueductos principales y las acequias mayores y menores o arrobas, conducen y distribuyen las aguas por los terrenos de cultivo. El carácter limo-arcilloso de las tierras de cultivo las hace propensas al encharcamiento. A fin de evitarlo, se construyó una segunda red de acueductos, destinada al drenaje de las aguas sobrantes de los cultivos, denominada de aguas muertas. Esta red reúne todas las aguas en sus acueductos principales, denominados azarbes, y bien las retorna directamente al río o bien las deriva hacia una tercera red de acueductos, conformando la red de aguas vivas reutilizadas. Esta tercera red toma las aguas de la red de aguas muertas y vuelve a distribuirlas para el riego de nuevos terrenos. Usa, por tanto, aguas reutilizadas de la red de aguas vivas. La denominación de estos acueductos es azarbe o acequia, según la jurisdicción a que pertenezcan.

Estas tres redes se componen de 63 acueductos, cuyas características más relevantes se han referenciado. En conjunto, suman una longitud total de 402,86 km, de los cuales 168,72 km (42\%) corresponden a la red de aguas vivas, $54,08 \mathrm{~km}(13 \%)$ a la red de aguas vivas reutilizadas y 180,06 km (45\%) a la red de aguas muertas.

Se han identificado los dos ciclos fundamentales y diferenciados que completan las aguas en los riegos tradicionales de la Vega Baja del Segura. El primero es el de la reutilización indirecta de las aguas del río, y el segundo el de la reutilización directa de las aguas, sin pasar por el río, mediante la red de acueductos de aguas vivas reutilizadas, en los propios azarbes. La reutilización directa de las aguas se realiza hasta dos veces (tres usos), dentro del sistema de los riegos tradicionales. Esta gestión de las aguas permite que del $100 \%$ de la superficie regada $\left(183,21 \mathrm{~km}^{2}\right)$, el $77 \%\left(140,52 \mathrm{~km}^{2}\right)$ se realice con la red de acueductos de aguas vivas procedentes del río y el restante $23 \%\left(42,69 \mathrm{~km}^{2}\right)$ con la red de acueductos de aguas vivas reutilizadas provenientes de otros regadíos.

Finalmente, puede afirmarse que el sistema de riego de los regadíos tradicionales de la Vega Baja del Segura es, desde un punto de vista cuantitativo, sumamente eficiente, puesto que las aguas dentro del sistema son aprovechadas al máximo. Todas las aguas derivadas del río, que viajan a través de la red de acueductos de aguas vivas, son utilizadas para el regadío, y las sobrantes son drenadas mediante la red de acueductos de aguas muertas y conducidas hacia el río, para ser indirectamente usadas de nuevo aguas abajo, o reutilizadas directamente en terrenos de cultivos próximos. Los caudales derivados pero que no son usados propiamente en el riego se encauzan hasta la red de acueductos de aguas muertas para su posterior uso. Al mismo tiempo, como las redes de acueductos de aguas vivas y de aguas muertas están canalizadas casi en su totalidad, las pérdidas por filtraciones, roturas, etc., son prácticamente nulas.

Por otro lado, la propia configuración del sistema de riego, con las redes de aguas vivas y de aguas muertas interconectadas, y donde la reutilización se realiza internamente en el sistema, supone que se aproveche la casi totalidad de los escasos recursos hídricos disponibles, usando las aguas hasta dos y tres veces, o, si se consideran las elevaciones finales, hasta tres y cuatro veces.

En cuanto a la eficiencia cualitativa del sistema, difiere de la cuantitativa. Inicialmente las aguas que llegan al sistema de riegos tradicionales de la Vega Baja del Segura ya son de poca calidad, con un alto 
contenido en sales ${ }^{1}$, y el proceso de reutilización dentro del sistema las empeora, si cabe, aumentando aún más la salinidad, perjudicando gravemente a lo largo del tiempo a las tierras de cultivo. No hay que olvidar que, aparte de las sales, las aguas van recogiendo los restos de los fertilizantes, productos fitosanitarios y vertidos incontrolados que, dados los bajos caudales, no se diluyen hasta alcanzar unos límites deseables, pudiendo afectar al rendimiento de los cultivos y al ecosistema formado alrededor de los azarbes, sobre todo al final del sistema. Se puede concluir, por tanto, que, cualitativamente, en la actualidad el sistema no es tan eficiente como antaño, cuando se disponían de más caudales y la presencia de elementos contaminantes era mucho menor.

\section{BIBLIOGRAFÍA}

ABADÍA, R., ORTEGA, J.F., RUIZ, A. y GARCÍA, T. (1999): “Análisis de la problemática del regadío tradicional de la Vega Baja del Segura. (I): situación actual y consideraciones sobre su modernización”. Riegos y Drenajes XXI, n 108, pp. 21-31.

ALONSO, R. (1950): El Cardenal Belluga y su Obra Colonizadora en las provincias de Murcia y Alicante. España.

AJUNTAMENT d’ELX y AIGÜES d’ELX: La cultura l'aigua a Elx a traves del temps.

BERNABÉ, D. (1998-99): "Insalubridad y bonificaciones de almarjales en el Bajo Segura antes de las Pías Fundacionales de Belluga”. Revista de Historia Moderna, n 17, pp. 45-72.

BERNABÉ, D. (2010): "Regadío y transformación de los espacios jurisdiccionales en el Bajo Segura durante la época foral moderna”. Investigaciones Geográficas, nº 53, pp. 63-84.

CALVO, F. (2005): Aguas Fluyentes: azudes y aceñas, en Gil, A. (Dir.): La cultura del agua en la cuenca del Segura. Murcia. Ed. Fundación Cajamurcia. Murcia, pp. 221-246.

CANALES, G. (2005): Avenamiento y utilización de aguas muertas, en Gil, A. (Dir.): La cultura del agua en la cuenca del Segura. Murcia. Ed. Fundación Cajamurcia. Murcia, pp. 403-479.

CANALES, G. y VERA, J.F. (1985): “Colonización del Cardenal Belluga en las tierras donadas por Guardamar del Segura: creación de un paisaje agrario y situación actual”. Investigaciones Geográficas, n 3.

CANALES, G. y LÓPEZ, A. (2011): "La extensión del regadío en el municipio de Orihuela y su repercusión en el territorio (1910-2010)". Papeles de Geografía, no 53-54, pp. 49-63.

DE GEA, M. (1992-93): "Sobre el establecimiento en su estructura inicial y fundamentos de la red de riego-drenaje principal del Bajo Segura”. Alebus, no 2-3, pp. 195-218.

DE GEA, M. (1995): "La construcción del paisaje agrario en el bajo Segura. De los orígenes hasta la implantación de la red de riego-drenaje principal en el alfoz oriolano". Alquibla, no 1, pp. 65-99.

DE GEA, M. (1997): "La formación y expansión decisiva de la huerta de Murcia-Orihuela: un enfoque desde la perspectiva de la Orihuela Musulmana (siglos VIII-XIII)". Alquibla, no 3, pp. 155-217.

DE GEA, M. (2010): "La huerta histórica del bajo Segura. Algunas claves sobre su formación, gestión del agua y situación e impactos actuales". Revista valenciana d'etnologia, no 5, pp. 55-70.

EZCURRA, J. (2007): El Plan de Defensa contra Avenidas de 1987 en la cuenca del Segura, en Plan de defensa de 1987 frente a avenidas en la cuenca del Segura. XX Aniversario. Ed. Confederación Hidrográfica del Segura, Ministerio de Medio Ambiente. Murcia, pp. 13-33.

EZCURRA, J. (2007): El encauzamiento del río Segura desde el límite de las provincias de Murcia y Alicante hasta Guardamar, en Plan de defensa de 1987 frente a avenidas en la cuenca del Segura. XX Aniversario. Ed. Confederación Hidrográfica del Segura, Ministerio de Medio Ambiente. Murcia, pp. 283-296.

EZCURRA, J. (1995): "Encauzamiento del río Segura desde la Contraparada (Murcia) hasta Guardamar del Segura (Alicante) y recuperación de los sotos del río. España”. Revista de Obras Públicas, n 3341, pp.39-51.

GALIANA, I. (1992): Yo, el Segura. Ed. Confederación Hidrográfica del Segura. España.

GENERALITAT VALENCIANA: Parc nutural El Fondo. Guía del Parque. Ed. Consellería de Medi Ambient, Aigua, Urbanisme i Habitatge.

GIL, A. (Dir.) (2005): La cultura del agua en la cuenca del Segura. Murcia. Ed. Fundación Cajamurcia.

\footnotetext{
1 Las aguas que llegan al final del sistema de los riegos tradicionales son ligeramente salobres, presentando una conductividad de entre 3.500 y $4.000 \mu \mathrm{S} / \mathrm{cm}$, lo que representa un $580 \%$ más que el agua de uso doméstico, cuya conductividad se sitúa entre 500 y $800 \mu \mathrm{S} / \mathrm{cm}$ (la conductividad del agua de mar es del orden de 52.000-56.000 $\mu \mathrm{S} / \mathrm{cm}$ ).
} 
GIL, A. y CANALES G. (1987): "Consolidación de dominios en las Pías Fundacionales del Cardenal Belluga (Bajo Segura)”. Investigaciones Geográficas, n 5, pp. 7-26.

GIL, A., OLCINA, J. y RICO, A.M. (2004): Aguaceros, aguaduchos e inundaciones en áreas urbanas alicantinas. Ed. Publicaciones de la Universidad de Alicante.

GIMÉNEZ, J.M. (2003): Riesgo de inundación y ordenación urbana en el litoral meridional alicantino. Ed. Publicaciones de la Universidad de Alicante.

GÓMEZ, J.L. y GRINDLAY, A.L. (Dirs.) (2008): Agua, Ingeniería y Territorio: La transformación de la cuenca del río Segura por la Ingeniería Hidráulica. Ed. Confederación Hidrográfica del Segura, Ministerio de Medio Ambiente, Medio Rural y Marino. España.

HERNÁNDEZ, C. (1990): La Vega Baja del Segura. Ed. Publicaciones de la Universidad de Alicante.

HURTADO, N. (1998): "La política agraria de Guardamar en el S. XVIII: aumento del regadio y alteración del término municipal”. Alquibla, nº 4, pp. 569-591.

JUZGADO PRIVATIVO DE AGUAS DE ORIHUELA (1946): Ordenanzas para el Gobierno y distribución de las aguas que riegan la huerta y otros pueblos sujetos al Juzgado Privativa de la misma. Imp. Imprenta Zerón. Orihuela.

MELGAREJO, J. y LÓPEZ, M.I. (2009): Historia del trasvase Tajo-Segura, en MELGAREJO, J. (Dir.), El trasvase Tajo-Segura: repercusiones económicas, sociales, y ambientales en la cuenca del Segura. Ed. Caja Mediterráneo. Alicante, pp. 37-113.

MELGAREJO, J. y MIRANDA, A. (2012): El patrimonio histórico natural. El valle de Ricote, El Hondo y las lagunas de Torrevieja, en BARCIELA, C., LÓPEZ, M. I. y MELGAREJO, J. (EDS.), Los bienes culturales y su aportación al desarrollo sostenible. Ed. Universidad de Alicante. Alicante, pp. 221-263.

MELGAREJO, J., TRAPOTE, A. y ROCA, J.F. (2013): "La infraestructura hidráulica y la gestión del agua en los regadíos tradicionales de la Vega Baja del Segura (Alicante)”. Pilquen (Sección Agronomía), año $\mathrm{XV}, \mathrm{n}^{\mathrm{o}} 13$, pp. 1-20.

MORALES, A.J., RICO, A.M. y HERNÁNDEZ, M. (2005): "El trasvase Tajo-Segura". Observatorio Medioambiental, n'8, pp. 73-110.

MUÑOZ, J. (2008): Encauzamiento del río Segura en Orihuela, en Plan de defensa de 1987 frente a avenidas en la cuenca del Segura. XX Aniversario. Ed. Confederación Hidrográfica del Segura, Ministerio de Medio Ambiente. Murcia, pp. 297-307.

PARRA, J. (1997): “El Reguerón, cáncer de la Vega Baja”. Alquibla, no 3, pp. 359-360.

PARRA, J. (1998): “Canalización del río Segura y sus improvisaciones”. Alquibla, no 4, pp. 673-675.

PARRA, J., PARRA, G., et al. (2006): "Riego y drenaje en la margen izquierda de la Vega Baja del Río Segura”. Riegos y Drenajes XXI, nº 146, pp. 60-64.

PARRA, J. y ABADÍA, R. (1999): "Evolución de la calidad del agua en el río Segura. El sistema tradicional de riego y las obras de aprovechamiento". Alquibla, n'5, pp. 167-183.

RAMÍREZ, A. (2005): El río Segura y su red de afluentes. Las ramblas. en Gil, A. (Dir.): La cultura del agua en la cuenca del Segura. Murcia. Ed. Fundación Cajamurcia 61-89.

ROCA DE TOGORES, J. (1832): Memoria sobre los riegos de la huerta de Orihuela. Impr. Benito Monfort. Valencia.

RUIZ, A. y MELIÁN, A. (2006): "Actividad agraria en las comarcas del sur de Alicante y competencias con otros sectores por los usos del agua y del suelo". Papeles de Geografía, no 43, pp. 105-119.

SEGURA, C. (Coord.) (2002): Historia de los regadíos de España (...a.C. - 1931). Ed. Misterio de Agricultura, Pesca y Alimentación. España.

TOMÁS, R., CUENCA, A., et al. (2010): “Cálculo analítico de la presión de preconsolidación del suelo: aplicación a la Vega Baja del río Segura (Alicante)”. Ingeniería Civil, no 157, pp. 97-107.

TOMÁS, R., CUENCA, A., et al. (2004): “Diseño de un modelo geológico-geotécnico 3D de la Vega Baja del río Segura (Alicante, SE España)". XVI Congreso Internacional de Ingeniería Gráfica (INGEGRAF); 2004 jun., 3-4; Zaragoza y Huesca, España. 